\title{
Kliniğimizde Endoskopik Timpanoplasti Yapılan Hastaların Geriye Dönük Sonuçlarının Değerlendirilmesi: Tek Merkez Deneyimi
}

\section{Evaluation of Retrospective Results of Patients Undergoing Endoscopic Tympanoplasty in Our Clinic: Single Center Experience}

\author{
İsmail iYNEN ${ }^{1} \mathbb{D}$, Ali AKBAŞ $^{1}$ (D) , Müslüm AYRAL ${ }^{1}$ (D) Mustafa ÇOBAN $^{1}$ (D)
}

${ }^{1}$ Harran Üniversitesi Tıp Fakültesi, Kulak Burun Boğaz Hastalıkları Anabilim Dalı, Şanlıurfa, TÜRKiYE

Öz.

Amaç: Bu çalışma kliniğimizde endoskopik timpanoplasti yapılan hastaların geriye dönük verilerinin incelenmesi amacıyla yapıldı.

Materyal ve Metod: lışmamız Ocak 2018 ile Haziran 2019 tarihleri arasında Harran Üniversitesi Tıp Fakültesi Kulak Burun Boğaz hastalıkları kliniğinde endoskopik timpanoplasti yapılan ve takip edilen 60 hastanın verilerinin retrospektif olarak incelendiği bir çalışmadır. Cerrahi sonrası en az 3 ay süreyle takiplere gelen hastalar çalışmaya dahil edildi. Takiplere 3 aydan az takiplere gelen, endoskopik dışı yöntemle opere edilen, verilerine ulaşılmayan hastalar çalışma dışı bırakıldı. Hastaların Pre-op ve post op yapılan odyometrik değerleri karşılaştıııldı. Hastaların kontrollerinde greft başarısına bakıldı

Bulgular: Endoskopik timpanoplasti yaptığımız 60 hastanın 25'i erkek 35'i kadındı. Ameliyat öncesi hava kemik aralığı ortalaması $21.5 \pm 9.40 \mathrm{~dB}$ iken ameliyat sonrası takiplerde yapılan odyometride hava kemik aralığı ortalaması $13.1 \pm 7.68 \mathrm{~dB}$ olarak bulundu. Greft başarı oranı \%80 (48 hasta) idi.

Hastaların \%20'sinde (12 hasta) greftte açıklık mevcuttu. Hastaların 12(\%20) tanesi marjinal perfore, 6 (\%10) tanesi total perfore,42 (\%70) tanesi ise santral perfore idi. Hastaların $10(\% 6)^{\prime}$ ununda kemik çimento ile rekonstrüksiyon gerekti 3(\%5)'ünde ise ossiküler protez uygulandığı tespit edildi.

Sonuç: Sonuçta mikroskopla kıyaslandığında endoskopik timpanoplasti benzer başarı sonuçlarına sahip olup daha az invaziv ve hasta açısından daha konforlu olduğu saptandı.

Anahtar Kelimeler: Timpanoplasti, Endoskopik, Kemikçik zincir rekonstrüksiyonu

Abstract

Background: Our research was conducted to examine the retrospective data of patients who underwent Endoscopic Tympanoplasty in our clinic.

Materials and Methods: This study is a retrospective study of the data of 60 patients who underwent endoscopic tympanoplasty and followed up in Harran University Faculty of Medicine Otorhinolaryngology clinic from January 2018 to June 2019. Patients who were followed for at least 3 months after surgery were included in the study. Patients who were operated with a non-endoscopic method and whose data were not available were excluded from the study. Pre-op and post-op audiometric values of patients were compared. The success of the graft was checked in the patients' controls.

Results: Of the 60 patients we underwent endoscopic tympanoplasty, 25 were male and 35 were female. While preoperative air bone gap mean was $21.5 \pm 9.40 \mathrm{~dB}$, the mean air bone gap was $13.1 \pm 7.68 \mathrm{~dB}$ in the audiometry performed during postoperative follow-up. The graft success rate was $80 \%$ ( 48 patients). In $20 \%$ of the patients (12 patients) there was a graft patency. $12(20 \%)$ of the patients were marginal perforated, $6(10 \%)$ were total perforated, $42(70 \%)$ were central perforated. Bone cement reconstruction was required in $10(6 \%)$ patients and ossicular prosthesis was applied in $3(5 \%)$ patients.

Conclusion: As a result, when compared with microscope, endoscopic tympanoplasty has similar success results and it was found to be less invasive and more comfortable for the patient.

Key Words: Tympanoplasty, Endoscopic, Ossicular chain reconstruction,
Sorumlu Yazar/Corresponding Author

Dr. İsmail iYNEN

Harran Üniversitesi Tıp Fakültesi Kulak Burun Boğaz Hastalıkları Anabilim Dalı, Osmanbey Kampüsü

Şanlıurfa, TÜRKIYE

E-mail: iiynen@hotmail.com

Geliş tarihi / Received: 14.06.2020

Kabul tarihi / Accepted: 05.05.2021

DOI: $10.35440 /$ hutfd. 752677

Bu çalışma 16.11.2019 tarihinde 41.Türk KBB-BBC Ulusal Kongresi'nde sözlü sunulmuştur. 


\section{Giriş}

Kronik otitis media (KOM), timpanik membranda ve orta kulak yapılarında kalıcı değişikliklere yol açabilen otolojide en yaygın problemlerden biridir. Timpanoplasti, timpanik membranın yeniden yapılandırılmasını ve ses iletme mekanizmasının restorasyonunu amaçlayan cerrahi prosedürdür. Timpanik membran rekonstrüksiyonunda birçok yöntem bulunmaktadır. Bunlar postaurikular insizyonla greftleme, endoural, transkanal yaklaşım gibi birçok tekniği içermektedir. Bu tekniklerde greft olarak yağ, periost, kıkırdak, perikondrium ve temporal kas fasyası gibi materyaller kullanılmaktadır. Postoauriküler yaklaşım özellikle anteriyor kadran perforasyonlarında en çok tercih edilen yöntemdir. Endaural yaklaşımlar genellikle posterior yerleşimli perforasyonlarda etkili bir yöntem olmakla birlikte daha az invaziv ancak kullanımı kısıtlı bir timpanoplasti tekniğidir $(1,2)$. Günümüzde minimal invaziv yöntemler birçok cerrahide daha ön planda olmaktadır. Son 20 yılda otolojik ve nöro-otolojik cerrahide endoskop kullanımı hızla artmaktadır. Günümüzde, birincil veya yardımcı bir cihaz olarak endoskoplar, kronik otitis cerrahisi, stapes cerrahisi ve koklear implantasyon gibi hemen hemen her türlü orta kulak ameliyatında kullanılmaktadır. Bu anlamda endoskopik timpanoplasti kronik otit cerrahisinde daha az invaziv ve etkili bir cerrahi yaklaşım olarak görülmektedir $(3,4)$. Endoskopi kullanımının geniş bir görüş alanı sağlaması, açılı endoskop kullanımının anteriyor yerleşimli marjinal perforasyonlara daha kolay hakim olunmasını sağlaması, attik, hipotimpanum, sinüs timpani ve fasiyal reses gibi ulaşıması zor bölgelerin görülmesini daha kolaylaştırmaktadır (5).

Bu çalışmada endoskopik transkanal timpanoplasti yapılan hastalar ve elde edilen ameliyat başarı oranları literatür bilgileri eşliğinde sunuldu.

\section{Materyal ve Metod}

Harran Üniversitesi Tıp Fakültesi Kulak Burun Boğaz Anabilim Dalı'nda Ocak 2018-Ocak 2020 tarihleri arasında kronik otitis media tanısı ile endoskopik timpanoplasti uygulanan 60 hastanın dosyaları incelendi. Çalışmamız için Harran Üniversitesi Tıp Fakültesi Etik Kurulundan onay almıştır (Evrak no: 24lO9I2019-E.40409/09.09.2019) Hastaların tümünde genel anestezi altında transkanal endoskopik timpanoplasti uygulanmıştır. Yapılan cerrahi işlem başlangıçta perfore timpanik membran kenarları desepitelize edilerek, daha sonra anulusun $5 \mathrm{~mm}$ lateralinden dış kulak yolu cildine saat 6 ile 12 arasında olacak şekilde tam kat cilt insizyonu yapıldıktan sonra timpanomeatal flep eleve edilerek orta kulağa girilir. Daha sonra kemikçik sistem hareketi ve attik bölgesi kontrol edilir (Şekil 1). Kolesteatomu ve aktif enfeksiyonu olan hastalar bu çalışma dışında tutulmuştur. Hastaların tümünde greft olarak tragal kıkırdak perikondriyumu kullanılmıştır.
Hastaların postoperatif dönemde 1. hafta 1. ay 3. ay 6. ay ve 12. ay kontrolleri incelenip rapor haline getirilmiştir. 1 . ay sonunda greft başarısına ve ameliyat sonrası işitme değerlerine bakılmıştır. Odyometride 500-1000-2000-4000 $\mathrm{Hz}$ frekanslarında hava kemik aralıklarının ortalaması değerlendirildi. Ameliyat öncesi ve ameliyat sonrası odyolojik değerler not edilerek karşılaştırıldı. Cerrahi sonrası en az 3 ay süreyle takiplere gelen hastalar çalışmaya dahil edildi. Takiplere 3 aydan az takiplere gelen, endoskopik dışı yöntemle opere edilen, verilerine ulaşılmayan hastalar çalışma dışı bırakıldı.

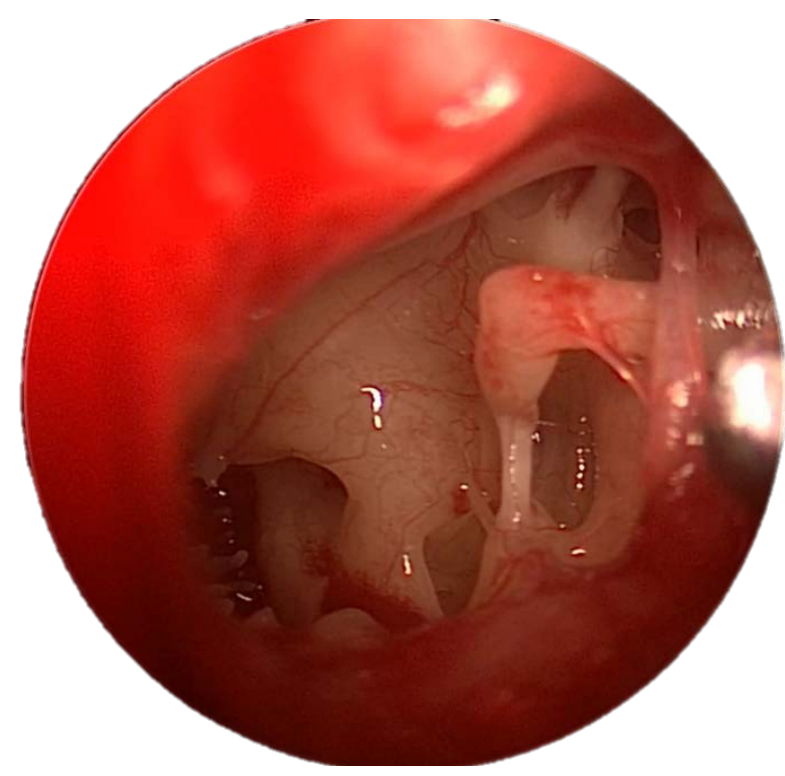

Şekil 1. Orta kulağın endoskopik görünümü

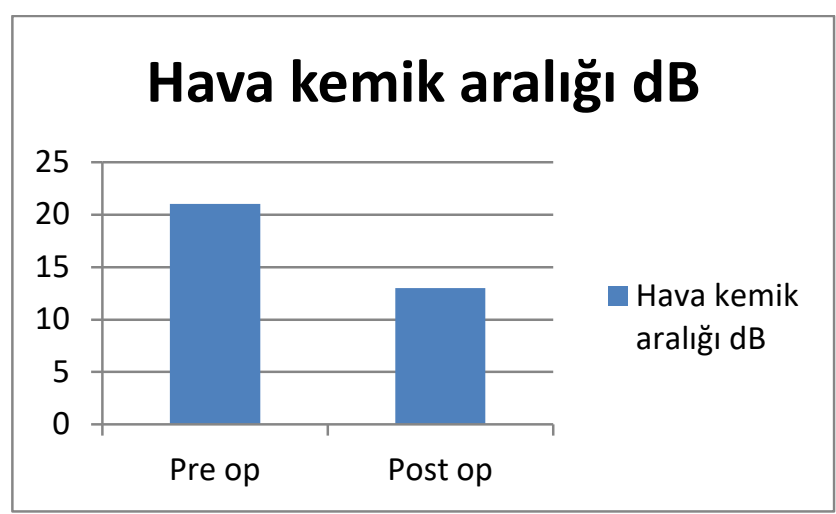

Şekil 2. Ameliyat öncesi ve ameliyat sonras hava kemik aralıklarının karşılaştırılması. 


\section{Bulgular}

Endoskopik timpanoplasti yaptığımız 60 hastanın (25 er-

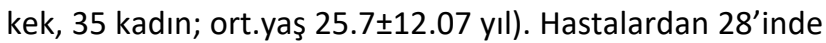
sağ kulak, 32'sinde sol kulak ameliyat edildi. Ameliyat öncesi hava kemik aralığı ortalaması $21.5 \pm 9.40 \mathrm{~dB}$ iken ameliyat sonrası takiplerde yapılan odyometride hava kemik aralığı ortalaması $13.1 \pm 7.68 \mathrm{~dB}$ olarak bulundu (Şekil 2). Hastaların yapılan takiplerinde 1 . ayında greft durumu değerlendirildi. Greft başarı oranı \%80 (48 hasta) idi. Hastaların \%20'sinde (12 hasta) greftte açıklık mevcuttu. Başarısız olan hastalardan 6 hastada ameliyat sonrası greft enfeksiyonu mevcuttu. Hastaların dosyaları incelendiğinde; 12 (\%20) tanesi marjinal perfore, 6 (\%10) tanesi total perfore, 42 (\%70) tanesi ise santral perfore idi. Hastaların 10 $(\% 6)^{\prime}$ ununda kemik çimento ile rekonstrüksiyon gerekti $3(\% 5)^{\prime}$ ünde ise ossiküler protez uygulandığı tespit edildi (Tablo1). Hastaların opresayon sonrası hastanede yatış süresi ortalama 24 saat idi. Hastaların ortalama takip süresi 6 (dağılım 1ay -12 ay) ay idi.

Tablo 1. Endoskopik Timpanoplasti Yapılan Hastaların Demografik ve Klinik Özellikleri $(n=60)$

\begin{tabular}{ll}
\hline Yaş Ortalaması(yıl) & $25.7 \pm 12.07$ \\
\hline Cinsyet & 25 \\
Erkek & 35 \\
Kadın & \\
Greft Başarısı & $48(\% 80)$ \\
\hline Başarılı & $12(\% 20)$ \\
Başarısız & \\
Perforafyon Tipi & $12(\% 20)$ \\
\hline Marjinal & $6(\% 10)$ \\
Total & $42(\% 70)$ \\
Santral & \\
Odyometri (Hava kemik aralığı ortalaması) & $21.5 \pm 9.40 \mathrm{~dB}{ }^{*}$ \\
\hline Perop & $13.1 \pm 7.68 \mathrm{~dB}$ \\
Postop & \\
Kemikçik Sisteme Yapılan işlemler & $10(\% 6)$ \\
\hline Kemik çimento uygulaması & $3(\% 5)$ \\
Protez uygulaması & \\
\hline dB: Desibel &
\end{tabular}

\section{Tartışma}

Timpanoplasti otolojik cerrahiler içerisinde en sık uygulanan yöntemlerden biridir. Klasik yöntemden ziyade minimal invaziv cerrahi birçok cerrahi alanda standart hale gelmektedir. KBB cerrahisinde endoskop otolojik ve nöro-otolojik prosedürlere dahil edilmiş yararlı bir araçtır. Geleneksel olarak mikroskobik görünüm altında gerçekleştirilen orta kulak prosedürleri giderek endoskopik olarak yapılmaktadır $(6,7)$. Mikroskopik tekniklerin en önemli avantajı iki elin kullanılabilmesi ve üç boyutlu görüş alanı sağlayabilmeleridir. Buna rağmen endoskopik cerrahilerde görüntü iki boyutludur ve tek el kullanılmaktadır. Bu durum derinlik algısında zorluğa neden olabilir (8). Mikroskobik transkanal yaklaşımda perforasyonun ön kenarının görüntülenmesi zor olabilmekte, olguların\%12'sinde perforasyon kenarlarının mikroskobik yaklaşımla tamamen görüntülenemediğini bildirmişlerdir (9).
Endoskopiki eşliğinde yapılan kulak cerrahisi dar kulak kanallarına sahip hastalarda, ön timpanik membran perforasyonlarının varlığında, kulak kanalında kemik çıkıntıları olan hastalarda ve perforasyon kenarlarının kolayca görüntülenemediği durumlarda faydalı olabilir. Orta kulak cerrahisi sırasında endoskopik prosedürlerin ana avantajlarından biri, ameliyat süresinde bir azalmadır. Endoskopik yaklaşım kozmetik görünüm, postoperatif ağrı ve pansuman gereksinimi açısından daha iyi sonuçlar verdiği rapor edilmiştir (10). Bununla birlikte, orta kulak ameliyatlarında endoskopinin uygulanmasında hala bazı kısıtlamalar bulunmaktadır. Endoskopiki eşliğinde yapılan kulak cerrahisinde uzun bir öğrenme eğrisi ve enstrümantasyon ve endoskopik tekniklerle ilişkili bazı zorluklar vardır. Kulakta küçük çaplı endoskopların kullanımı deneyimsiz cerrahlar için zor olabilir ve bu, endoskopinin mikroskopiye göre ana avantajı olan geniş açılı görüntüler elde etme fırsatını engeller. Endoskopik kulak cerrahisi ile ilgili iki önemli dezavantaj vardır. Birincisi ışık kaynağı tarafından üretilen ISı, özellikle ksenon ışık kaynakları tarafından salınan ısıdır (11). Bu soruna bir çözüm olarak, rutin olarak kullanılan ışık kaynağı daha düşük bir güç seviyesinde çalışacak şekilde ayarlanabilir. Literatürde timpanik membran perforasyonlarının endoskopik transkanal tedavisi için genel kapanma oranının\%84 ile \%96 arasında olduğu bildirilmektedir (12). Çalışmamıza benzer olarak Ayache'nin yaptığı çalışmada, kıkırdak ile transkanal endoskopik timpanoplasti uygulanan hastalarda greft kapanma oranının \%96 olduğunu bildirmiş ve bu prosedürün minimal invaziv, güvenli ve etkili bir tedavi olduğunu rapor edilmiştir. Yazar ameliyat öncesi hava kemik aralığını 17.9 dB'den ameliyat sonrası 7.9 dB'ye düştüğünü tespit etmiştir (13). Geleneksel olarak, tip I timpanoplasti için mikroskobik teknikler,\%78 ila \%90 arasında değişen bir kapanma oranı sunar. Philips ve ark. ları ile Nardone ve ark. larının yaptıkları çalışmalarda, hastaların \% 61 'i $10 \mathrm{~dB}$ 'de bir azalma ile birlikte ortalama $9.1 \mathrm{~dB}$ hava kemik aralığını kazanımı elde edilmiştir $(14,15)$. Bizim çalışmanın temel kısıtılığı mikroskopik kulak cerrahisi ile kantitatif bir karşılaştırmanın olmamasıdır. Diğer bir sınırlama ise, mevcut çalışma toplanan hasta sayısının (60) düşük olmasıdır. Bu çalışmada sunulan verileri doğrulamak için daha geniş bir hasta örneği de dahil olmak üzere daha fazla çalışmaya intiyaç duyulacaktır.

\section{Sonuç}

Endoskopik timpanoplasti tekniği minimal invaziv bir teknik olup, perforasyonun boyutundan bağımsız olarak başarılı sonuçlar sağlayabilmektedir. Transkanal uygulanabilmesi, dışarıdan inzisyon gerekliliği olmaması, hastanede yatış süresinin kısa olması diğer tekniklere göre olan avantajlarıdır. 
Etik onam: Çalışmamız için Harran Üniversitesi Tıp Fakültesi Etik Kurulundan onay almıştır.

(Evrak no: 24lO9/2019-E.40409/09.09.2019).

\section{Yazar Katkıları:}

Konsept: i.i

Literatür Tarama: i.i., M.A.

Tasarım: i.i., M.A.

Veri toplama: A.A., M.A., M.Ç.

Analiz ve yorum: i.i., M.A.

Makale yazımı: i.i., M.A.

Eleştirel incelenmesi: i.i., M.A., M.Ç.

Çıkar Çatışması: Herhangi bir çıkar çatışmamız bulunmamaktadir.

Finansal Destek: Araştırma kapsamında herhangi bir kurum ya da kuruluştan finansal destek sağlanmamıştır.

\section{Kaynaklar}

1. Jako GJ. Postauralversusendauralexposure in tympanoplasty. Laryngoscope1967;77:2022-31.

2. Halim A, Borgstein J. Pediatricmyringoplasty: postauralversustransmeatalapproach. Int J PediatricOtorhinolaryngol2009;73:1580-3.

3. Tarabichi M. Endoscopicmanagement of acquiredcholesteatoma. Am J Otol1997;18:544-9.

4. Kakehata $S$, Watanabe $T$, Ito $T$, Kubota $T$, Furukawa $T$. Extension of indicationsfortranscanalendoscopicearsurgeryusing an ultrasonic bone curetteforcholesteatomas. OtolNeurotol2014;35:101-7

5. Patil RN. Endoscopictympanoplasty-Definitelyadvantageous. Asian J EarNoseThroat2003;25:9-13.

6. Marchioni D, Alicandri-Ciufelli M, Molteni G, Genovese E, Presutti L. Endoscopictympanoplasty in patientswithatticretractionpocketsLaringoskop 2010; 120: 1847-1855 ,

7. Marchioni D, Mattioli F, Alicandri-Ciufelli M, Presutti L. Transcanalendoscopicapproachtothesinustympani: a clinicalreport. OtolNeurotol 2009; 30: 758-765

8. Mohindra S, Panda NK. Earsurgerywithoutmicroscope; is it possible. Indian J OtolaryngolHeadNeckSurg2010;62:138-41.

9. Furukawa $T$, Watanabe $T$, Ito $T$, Kubota $T$, Kakehata $S$. Feasibilityandadvantages of transcanalendoscopicmyringoplasty. OtolNeurotol 2014; 35: e140-E145.

10. Himani L, Santosha RC, Ashish V. Endoskopik ve mikroskopikmiringoplasti: Farkl । bir bakış açısı. EurArchOtorhinolaryngol 2014; 271: 1897-1902.

11. Dundar R, Bulut $H$, Güler OK, Yükkaldiran $A$, Demirtaş $Y$, Iynen I et al. Oval WindowTemperatureChanges in an EndoscopicStapedectomy. J CraniofacSurg. 2015; 26(5):1704-8.

12. Garcial B, Moussalem GF, Andrade JS, Mangussi-Gomes J, Cruz OLM, Penido NO. Transcanal endoscopic myringoplasty: a caseseries in a universitycenter. Otorhinolaryngol 2016; 82: 321-325. 35.

13. Braz J Ayache $S$. Cartilagemiringoplasty: endoscopictranscanalprocedureEurArchivesOtorhinolaryngol 2013; 270: 853-860.

14. Nardone M, Sommerville R, Bowman J, Danesi G. Myringoplasty in simplechronicotitismedia: criticalanalysis of long-termresults in a 1,000-adult patientseries. OtolNeurotol 2012; 33: 48-53.

15. Phillips JS, Yung MW, Nunney I. Myringoplastyoutcomes in the UK. J LaryngolOtol 2015; 129: 860-864. 